\title{
Comparison of obstetric outcomes with use of two different standard doses of oxytocin for induction of labor
}

\author{
Alka Gupta, Rucha Thakare*, Madhva Prasad \\ Department of Obstetrics and Gynecology, Seth G. S. Medical College and KEM Hospital, Mumbai, Maharashtra, \\ India
}

Received: 15 April 2020

Accepted: 06 May 2020

*Correspondence:

Dr. Rucha Thakare,

E-mail: rthakare251@gmail.com

Copyright: () the author(s), publisher and licensee Medip Academy. This is an open-access article distributed under the terms of the Creative Commons Attribution Non-Commercial License, which permits unrestricted non-commercial use, distribution, and reproduction in any medium, provided the original work is properly cited.

\begin{abstract}
Background: The interventions used in a suspected abnormal labor include amniotomy (artificial rupture of membranes), oxytocin infusion, forceps application and caesarean section. No study is available for individualised treatment with oxytocin. Considering the literature review, many unanswered questions remain regarding the use of oxytocin and definite improvements are possible. All this led us to choose this as the topic for study.

Methods: This study was conducted over a duration of 18 months (January 2017 to June 2018) where ninety (90) laboring patients admitted in a tertiary care hospital were included. They were categorized into two groups, one group (30 patients) received the low dose and the other group (60 patients) received high dose oxytocin infusions. The labor outcomes including the maternal and fetal outcomes were observed.

Results: The average age in the study population was 26 years and the average gestation was 38 weeks. The overall rate of cesarean section in this study was $16.67 \%$ (23.33\% in the low dose group and $13.33 \%$ in the high dose group). Gravidity and parity have an association with the vaginal delivery.

Conclusions: It is safe to use oxytocin infusion either in the low dose or the high dose for induction of labor as both the regimens are equally effective and comparable in terms of outcomes. The low dose oxytocin regimen can be safely recommended in a patient requiring oxytocin infusion for induction of labor and the treating doctor should consider starting with low dose oxytocin.
\end{abstract}

Keywords: Amniotomy, Oxytocin, Induction

\section{INTRODUCTION}

Theobald and associates in 1948 described the use of oxytocin for induction of labor. ${ }^{1}$ In response to stretching of cervix and uterus during labor and stimulation of nipples during breastfeeding, oxytocin is released into circulation.

The interventions used in a suspected abnormal labor include amniotomy (artificial rupture of membranes), oxytocin infusion, forceps application and caesarean section. ${ }^{2,3}$ Current guidelines for the use of oxytocin in abnormal labor suggest a continuous infusion. Various regimens have been described for oxytocin use in labor; low dose, high dose, increased frequency and pulsatile preparations. $^{4}$

\section{Aims and objectives}

To compare obstetric outcomes with use of two different standard doses of oxytocin for induction labor.

\section{Primary objectives}

- Induction to optimal uterine contractions interval.

- Induction to successful vaginal delivery interval. 
- Maternal complications

- Apgar scores and neonatal outcome.

\section{Secondary objectives}

- Incidence of emergency lower segment caesarean section due to failure of induction, or reasons other than failure of induction

- Incidence and effects of hyperstimulation of uterus ( $>5$ uterine contractions in 10 minutes averaged over 30 minutes observation period).

\section{METHODS}

The study was a comparative, observational, prospective study and performed on the patients admitted in the labor ward of department of obstetrics and gynecology of a tertiary care hospital. This study was conducted over a duration of 18 months (January 2017 to June 2018).

\section{Inclusion criteria}

- Patients willing to participate, permitting access to their labor records and providing consent for the study

- Patients requiring induction of labor with favorable Bishop's score. (Bishop score $>5$ )

- Patients with fetus in the vertex presentation and no contraindication to vaginal birth

- Low risk patients of $>37$ weeks of gestational age

- Patients of PROM, postdated, post term pregnancy, gestational hypertension, intrauterine fetal death, oligohydramnios.

\section{Exclusion criteria}

- Patients with previous lower segment caesarean section or previous operative procedures on uterus (myomectomy/ hysterotomy)

- Patients with cephalopelvic disproportion

- Patients with malpresentation of fetus

- Patients with severe preeclampsia, eclampsia, cardiac diseases, chronic renal diseases with altered renal function tests

- Patients with multi fetal pregnancy

- Patients with cervical ripening done by chemical method such as PG E2 gel or PG E1.

Patients were included in the study as per the selection criteria and categorized into the two groups. The routine management of antenatal/medical problems and labor/delivery were continued by her treating doctors, under whom she was admitted.

The decision of the treating doctor with the dose of oxytocin used (either low dose or the high dose) was noted and the same was explained to the patient and the relatives. Informed consent was taken from the patient and the relatives when the decision of induction of labor using oxytocin was made. Relevant data including age, parity, previous obstetric and operative history, medical co-morbidities were noted. All investigations were noted.

\section{The two regimes that are used are}

- The low dose oxytocin i.e. $2 \mathrm{mU} / \mathrm{min}$ with incremental increase by $2 \mathrm{mU} / \mathrm{min}$ every 30 minutes

- The high dose oxytocin regime i.e. $5 \mathrm{mU} / \mathrm{min}$ with incremental increase by $5 \mathrm{mU} / \mathrm{min}$ every 30 minutes.

Titration stopped when the maximum infusion reaches 40 $\mathrm{mU} / \mathrm{min}$ or adequate contractions (consistent achievement of 1 contraction every 2-3 minutes lasting for 80-90 seconds palpating strong with adequate relaxation between contractions) are achieved whichever is earlier. The infusion flow rate and dose administration were controlled by dial flow which is the standard method of administering the oxytocin infusion.

Abdominal examination was done every 30 minutes and vaginal examination was repeated after every 2 hours. Maternal outcome was measured in terms of duration of labor, mode of delivery and complications during the labor. Indications for emergency caesarean section were noted.

The partograph maintained during monitoring were also studied. Fetal outcome was measured in terms of Apgar score at 0,5 and 10 minutes, incidence of birth asphyxia, cord $\mathrm{pH}$, need for NICU admission and duration of hospital stay and perinatal mortality.

End point: delivery: vaginal or caesarean birth.

Failure of induction was defined as: failure to generate regular contractions approximately every three minutes and cervical change after at least 24 hours of oxytocin administration.

After the delivery it was stated whether it was a successful or failed induction as per the criteria of the definition above.

\section{Statistical analysis}

The basic parameters of the patients were calculated and represented graphically as tables or bar diagrams. The statistical analysis was done using. Chi square test, Mann Whitney $\mathrm{U}$ test and Unpaired t-test.

\section{RESULTS}

A total 90 women were included in this study, 46 primigravidae and 44 multigravidas.

The most common indications for oxytocin infusion in this study were PROM, following mechanical cervical ripening and following sweeping of the lower membranes. 
A total $76.67 \%$ women in the low dose group and $96.67 \%$ women in the high dose group had achieved optimal contractions when oxytocin was infused for 4-8 hours

Table 1: The overall general parameters of the participants included in the study.

\begin{tabular}{|llll|}
\hline Parameters & Mean & Median & $\begin{array}{c}\text { Standard } \\
\text { deviation }\end{array}$ \\
\hline Age (in years) & 26.11 & 26 & 4.25 \\
\hline Weeks of gestation & 38.6 & 39 & 1.35 \\
\hline Gravida & 1.7 & 1 & 0.82 \\
\hline Parity & 0.46 & 0 & 0.67 \\
\hline Bishop score & 7.18 & 7 & 0.93 \\
\hline
\end{tabular}

It was noted that the proportion of women who had achieved optimal contractions was highest at 8 hours of oxytocin infusion $(78.26 \%$ in the low dose group and $96.36 \%$ in the high dose group).

The overall rate of caesarean section in this study was $16.67 \%$ (23.33\% in the low dose group and $13.33 \%$ in the high dose group) and the most common indication for the caesarean section was fetal distress.

A higher proportion of women from the low dose group (43.47\%) had delivered within 2 hours of achieving optimal contractions as compared to the high dose group $(18.18 \%)$.

Table 2: Distribution of mode of delivery between the two study groups.

\begin{tabular}{|lllll|}
\hline Dose of oxytocin & Number of participants & Vaginal delivery $(\%)$ & Abdominal delivery (\%) & Fisher's \\
Low dose oxytocin & 30 & $23(76.67 \%)$ & $7(23.33 \%)$ & $8(13.33 \%)$ \\
\hline High dose oxytocin & 60 & $52(86.67 \%)$ & $15(16.67 \%)$ & p-value \\
\hline Total & 90 & $75(83.33 \%)$ & $\mathbf{0 . 2 4 4 6}$ \\
\hline
\end{tabular}

Table 3: Comparison of Mode of delivery against gravidity and oxytocin dose.

\begin{tabular}{|llll|}
\hline Gravida 1 & Low dose (14) & 10 & 4 \\
\hline & High dose (32) & 24 & 8 \\
\hline Gravida $\geq 2$ & Low dose (16) & 13 & 3 \\
\hline & High dose (28) & 28 & 0 \\
\hline
\end{tabular}

Table 4: Comparison of Mode of delivery against gravidity (irrespective of oxytocin dose).

\begin{tabular}{|lll|}
\hline & FTND & LSCS \\
\hline Gravida 1 (46) & $34(73.91 \%)$ & $12(26.08 \%)$ \\
\hline Gravida $\geq 2(44)$ & $41(93.18 \%)$ & $3(6.81 \%)$ \\
\hline
\end{tabular}

Table 5: Comparison of mode of delivery against parity and oxytocin dose.

\begin{tabular}{|llll|}
\hline \multirow{2}{*}{ Para 0 } & & FTND & LSCS \\
\cline { 2 - 4 } & Low dose (19) & 14 & 5 \\
\hline \multirow{2}{*}{ Para $\geq 1$} & High dose (38) & 30 & 8 \\
\cline { 2 - 4 } & Low dose (11) & 9 & 2 \\
\hline
\end{tabular}

Gravidity and parity have positive association with the vaginal delivery as higher percentage of women with gravidity of order 2 and above had vaginal delivery in this study $(93.18 \%$ compared to $73.91 \%$ in the primigravidae). Similarly, parous women had higher percentage of vaginal delivery $(93.93 \%$ compared to $77.19 \%$ in the nullipara).
Table 6: Comparison of Mode of delivery against parity (irrespective of oxytocin dose).

\begin{tabular}{|lll|}
\hline & FTND & LSCS \\
\hline Para 0 (57) & $44(77.19 \%)$ & $13(22.80 \%)$ \\
\hline Para $\geq 1(33)$ & $31(93.93 \%)$ & $2(6.06 \%)$ \\
\hline
\end{tabular}

Table 7: Mode of delivery compared against Bishop Score.

\begin{tabular}{|lll|}
\hline Bishop score & FTND & LSCS \\
\hline$\leq 7(64)$ & $53(82.81 \%)$ & $11(17.18 \%)$ \\
\hline$>7(26)$ & $22(84.61 \%)$ & $4(15.38 \%)$ \\
\hline
\end{tabular}

The proportion of women who delivered vaginally was comparable at an average Bishop score of 7.

No participant from the either study group had uterine hyperstimulation or tachysystole after oxytocin infusion. One patient from the high dose oxytocin group had postpartum hemorrhage after vaginal delivery which was medically managed. No surgical intervention or blood transfusion was required. No fetal or neonatal complications were noted during this study.

The average duration of hospital stay was 6 days, irrespective of the dose of oxytocin used for labor induction and the mode of delivery.

\section{DISCUSSION}

Oxytocin is one of the most common methods used for induction as well as augmentation of labor. The results 
from this study were analysed and the same were compared with the studies available.

Age

The least age encountered was 19 years and the eldest participant was of 38 years of age in this study. The average age in the low dose group was 26.5 years and that in the high dose group was 25.8 years, stating that both groups were comparable. Also, there was no difference in the response of the study participants. In the study by Kenyon et al, less than 16 years of age was taken as exclusion criteria. ${ }^{5}$ However, in the study by Selin et al, they had excluded women less than 18 years of age. The average age in their study was 29 years. ${ }^{6}$ In this study, it was 26 years, which is comparable (Table $1)$.

\section{Gestational age}

Study included women with gestational age of 37 weeks or more (maximum 42 weeks). The two study groups were similar in terms of gestational age of the participants ( $\mathrm{p}$ value 0.4706 ).

Among those with gestational of 39 weeks and less, $11.76 \%$ patients had LSCS in the low dose group while the percentage in the high dose group was $7.89 \%$. In those with gestational age of more than 39 weeks, LSCS rates in the low dose and the high dose group were $38.46 \%$ and $22.72 \%$ respectively. This data clearly states that the LSCS rate was more with increased gestational age irrespective of the dose of oxytocin used.

In the study by Selin et also, they had the inclusion criteria of 37 weeks and above (with higher limit of $41+6$ weeks). ${ }^{6}$ These were similar in the study by Kenyon et al also. ${ }^{5}$ Similarly in the systematic review by Budden et al, they found that majority of the studies included women with completed 37 weeks for comparison of efficacy of various doses of oxytocin. ${ }^{7}$ Authors have followed a similar pattern.

\section{Mode of delivery}

In the study by Kenyon, the outcomes with two doses of oxytocin were compared. They had included 47 women in each group. The low dose oxytocin group had a cesarean section rate of $32 \%$ whereas the high dose group had $36 \%$ of women going for cesarean section. ${ }^{5}$

In the same study, the rate of vaginal delivery was $21 \%$ and $26 \%$ in the low and high dose oxytocin groups respectively whereas the rate for instrumental delivery was $45 \%$ in the low dose group and $36 \%$ in the high dose group. ${ }^{5}$

In this study, authors had included 30 women in the low dose group and 60 in the high dose group. Authors found the cesarean rate to be $23.33 \%$ and $13.33 \%$ in the low dose and the high dose oxytocin group respectively (Table 2) However, the value was not statistically significant.

In this study, the rate of vaginal delivery was $73.33 \%$ in the low dose group and $86.67 \%$ in the high dose group (Table 2). The rate of instrumental delivery was $3.33 \%$ in the low dose group. No patient in the high dose group had instrumental delivery. Yet again, there seems to be lot of difference between this study results and those done elsewhere. This may be explainable because of the variation in sample size, local practices and titration methods. Variations in labor management guidelines of individual institutes can also lead to such inconsistencies.

\section{Gravida/parity status}

In this study, there were 46 primigravidae and 44 multigravidae. Those with higher order gravida had higher rate of vaginal deliveries (Table 3, 4). Most studies have matched and compared equal number of patients based on parity. In this study also, authors found that parity had an influence on the response of oxytocin. Women with higher parity had better response to oxytocin, thereby resulting in higher rate of vaginal deliveries (Table 5,6). This was immaterial of the dosage of oxytocin.

A subgroup analysis from few trials based on parity was done by Budden et al. There was no effect of parity status on mode of delivery, in both the study groups (low dose and high dose oxytocin group). ${ }^{7}$

\section{Bishop score at the time of start of oxytocin infusion}

Bishop score denotes the favorability of cervix for induction of labor. With a favorable cervix any method of induction helps and mostly oxytocin and/or amniotomy is used. ${ }^{8}$

In this study, among those patients who had a Bishop score of 7 and less, $82.81 \%$ had vaginal delivery. The remaining $17.18 \%$ had LSCS. For those with Bishop score of more than $7,84.61 \%$ patients delivered vaginally and $15.38 \%$ had LSCS (Table 7). Authors found no statistically significant difference with $p$ value of 0.79234 by the Mann-Whitney U-test.

Middleton et al have presented a report of 30 randomized controlled trials on 12,479 women for labor induction at term and beyond. Almost all the studies used Bishop score as a criteria for deciding the mode of intervention. ${ }^{9}$

\section{Dose of oxytocin used}

In this study the two groups of oxytocin, low dose and the high dose, titration of oxytocin was done according to the uterine activity. Authors found that when the oxytocin infusion was continued for 8 hours, a comparable proportion of women in both the groups had achieved 
optimal contractions. This showed that when the oxytocin infusion is continued for appropriate time even a good proportion of women who received low dose oxytocin can achieve optimal uterine contractions and have a comparable outcome with the high dose group.

A randomized controlled trial by Selin L et al, carried out in Sweden in the year 2018 compared the high dose and low dose regimen of oxytocin for labor augmentation in 2195 women (high-dose $n=647$; low-dose $n=648$ ). The primary objective was to study the cesarean section rate when two different dose regimens were used in the nulliparous women. Nulliparous women with singleton pregnancy and cephalic presentation at term with delayed labor were included in this trial.

There was no significant difference found in the cesarean section rates between the two groups $(12.4 \%$ and $12.3 \%$, 95\% confidence interval: 3.7 to 3.8 ). However, those in the high dose oxytocin group had shorter duration of labor (by an average of 23.4 minutes) and more incidences of uterine tachysystole (43.2\% versus $33.5 \%)$. The rate of instrumental vaginal delivery was comparable but the fetal distress was an indication in a greater number of cases in the high dose group $(43.8 \%$ versus $22.7 \%)$ than the failure to progress $(39.6 \%$ versus $58.8 \%$ ). This study could not find a clear indication for the routine use of the high dose regimen in cases of delayed labor. However, use of low dose oxytocin regimen was recommended to avoid the chances of uterine tachysystole and fetal distress. ${ }^{6}$

\section{Maternal complications}

In the same study Selin L et al, the percentage of patients who had postpartum hemorrhage (blood loss $>1000 \mathrm{ml}$ ) was $14.4 \%$ and $13.6 \%$ in the low dose and the high dose oxytocin group respectively. ${ }^{6}$

In this study, one patient from the high dose group who delivered vaginally without any instrumentation had an episode of atonic PPH which was managed with medical methods. No surgical intervention or blood transfusion was required. None of the patients from the low dose group had postpartum hemorrhage.

Recently, Bostanci et al conducted a study to compare the effects of intermittent oxytocin usage as against continuous oxytocin infusion. In a population of 200 patients, who were randomized, it was found that though the rate of uterine hyperstimulation was $21 \%$ in the continuous infusion arm of the study. However, the intermittent usage group showed a much smaller incidence $(3.8 \%)$. In this study, there were no cases of uterine hyperstimulation. ${ }^{10}$

\section{Fetal complications (fetal distress)}

In a randomized controlled trial by Selin $\mathrm{L}$ et al carried out in Sweden in the year 2018 for comparing the high dose and low dose regimen of oxytocin for labor augmentation in 2195 women (high-dose $n=647$; lowdose $n=648$ ), the rate of instrumental vaginal delivery was comparable but fetal distress was an indication in more number of cases in the high dose group (43.8\% versus $22.7 \%$ ) than failure to progress $(39.6 \%$ versus $58.8 \%$ ). This study could not find a clear indication for the routine use of the high dose regimen in cases of delayed labor. However, use of low dose oxytocin regimen was recommended to avoid the chances of uterine tachysystole and fetal distress. ${ }^{6}$

In this study, in the low dose group, out of 30 women 7 had developed fetal distress before achieving the optimal uterine contractions and had LSCS. Out of 23 who achieved optimal uterine contractions, 2 had fetal distress in the second stage of labor and had instrumental delivery (outlet forceps) for the same indication (total 30\% in the low dose group). In the high dose group out of 60,2 women $(3.33 \%)$ had developed fetal distress and went for cesarean section, both before the optimal contractions could be reached.

\section{Duration of hospital stay}

The average duration of hospital stay in this study was 6 days both in the low dose and the high dose group, which was variable and not comparable because of multiple influencing factors like the maternal and the neonatal health post-delivery.

\section{Drawbacks and limitations}

This study was an observational study in which the indication, decision and the intervention taken for induction of labor was decided by the doctors primarily treating the patient, which varied according to the hospital working system. Also, the dose of oxytocin being used for a particular patient was decided by the treating doctor.

The clinical findings of the qualified staff members which were included during the data collection had interobserver bias as the same qualified staff member has not examined all the patients neither a particular patient was examined by the same person throughout her labor.

\section{ACKNOWLEDGMENTS}

Authors would like to thank head of the department Dr. SV Parulekar, and the other unit heads Dr. PY Samant, Dr. HK Choudhary, Dr. H Warke, Dr. PA Hatkar for permitting us to recruit their patients for this observational study.

\section{Funding: No funding sources Conflict of interest: None declared \\ Ethical approval: The study was approved by the Institutional Ethics Committee}




\section{REFERENCES}

1. Theobald GW, Graham A, Campbell J, Gange PD, Driscoll WJ. The use of post-pituitary extract in physiological amounts in obstetrics; a preliminary report. Br Med J. 1948;2(4567):123-7.

2. Shu-Qin W, Zhong-Cheng L, Hui-Ping Q. High-dose versus low-dose oxytocin for labor augmentation: a systematic review. Am J Obstet Gynecol, 2010;203:296-304.

3. Wiberg-Itzel E, Akerud H, Andolf E, HellströmWestas L, Winbladh B, Wennerholm UB. Association between adverse neonatal outcome and lactate concentration in amniotic fluid. Obstet Gynecol, 2011;118:135-42.

4. Tribe RM, Crawshaw SE, Seed P, Shennan AH, Baker PN. Pulsatile versus continuous administration of oxytocin for induction and augmentation of labor: two randomized controlled trials. Am J Obstet Gynecol. 2012;206:230.e1-8.

5. Kenyon S, Armstrong N, Johnston T, Walkinshaw S, Petrou S, Howman A, et al. Standard or high-dose oxytocin for nulliparous women with confirmed delay in labour: quantitative and qualitative results from a pilot randomised controlled trial. BJOG. 2013;120(11):1403-12.

6. Selin L, Wennerholm UB, Jonsson M, Dencker A, Wallin G, Wiberg-Itzel E, et al. High-dose versus low-dose of oxytocin for labour augmentation: a randomised controlled trial. Women Birth. 2018:S1871-5192(18)30363-9.

7. Budden A, Chen LJ, Henry A. High-dose versus low-dose oxytocin infusion regimens for induction of labour at term. Cochrane Database Syst Rev. 2014;10:CD009701.

8. Wormer KC, Williford AE. Bishop Score. In: Stat Pearls. Treasure Island (FL): stat pearls publishing; 2018. Available https://www.ncbi.nlm.nih.gov/books/NBK470368/. Accessed on $10^{\text {th }}$ March 2020.

9. Middleton P, Shepherd E, Crowther CA. Induction of labour for improving birth outcomes for women at or beyond term. Cochrane Database Syst Rev. 2018;5:CD004945.

10. Bostancı E, Kilicci C, Ozkaya E, Abide YC, Eroglu M. Continuous oxytocin versus intermittent oxytocin for induction of labor: a randomized study. J Matern Neonatal Med. 2018;1-6.

Cite this article as: Gupta A, Thakare R, Prasad M. Comparison of obstetric outcomes with use of two different standard doses of oxytocin for induction of labor. Int J Reprod Contracept Obstet Gynecol 2020;9:2397-402. 